\title{
Dating of seasonal snow/firn accumulation layers using pollen analysis
}

\author{
Fumio NAKAZAWA, ${ }^{1 *}$ Koji FUJITA, ${ }^{2}$ Nozomu TAKEUCHI, ${ }^{3}$ Toshiyuki FUJIKI, ${ }^{2}$ \\ Jun UETAKE, ${ }^{4}$ Vladimir AIZEN, ${ }^{5}$ Masayoshi NAKAWO ${ }^{3}$ \\ ${ }^{1}$ Graduate School of Science, Nagoya University, Nagoya 464-8601, Japan \\ E-mail: nakazawa@shinshu-u.ac.jp \\ ${ }^{2}$ Graduate School of Environmental Studies, Nagoya University, Nagoya 464-8601, Japan \\ ${ }^{3}$ Research Institute for Humanity and Nature, Takashima-cho 335, Kyoto 602-0878, Japan \\ ${ }^{4}$ Faculty of Bioscience and Biotechnology, Tokyo Institute of Technology, Ookayama, Meguro-ku, Tokyo 152-8551, Japan \\ ${ }^{5}$ Department of Geography, College of Mines and Earth Resources, PO Box 443025, University of Idaho, Moscow,
} Idaho 83844-3025, USA

\begin{abstract}
Reliable chronologies in ice cores and snow pits from many alpine glaciers in latitudes between $60^{\circ} \mathrm{N}$ and $60^{\circ} \mathrm{S}$ are often difficult to establish owing to problems with annual-layer counting. Problems arise from melting, wind erosion and the negligible amount of precipitation in some seasons, all of which tend to obscure the seasonal variations in $\delta^{18} \mathrm{O}$ and chemical concentrations that are typically used to date ice cores. However, alpine glaciers contain many species of pollen grains that peak at particular times of the year. We used the peaks in Betulaceae, Pinus, Artemisia and a combination of Abies and Picea pollen species to determine the four seasonal layers of a snow pit on Belukha glacier in Russia's Altai Mountains. Comparing the pollen-dated profiles with wind and precipitation records allows us to determine where a seasonal layer is missing. Thus, the pollen-dating method described here may be a useful tool to measure the annual snow deposition on alpine glaciers, even when some seasonal layers are eroded by wind or missing due to negligible precipitation.
\end{abstract}

\section{INTRODUCTION}

Studies of deep ice cores from Greenland and Antarctica have proven crucial for reconstructing the past environmental history of polar regions (e.g. Lorius and others, 1990; Grootes and others, 1993; Jouzel and others, 1993; McManus and others, 1994). In addition to the information from those regions, ice cores from alpine glaciers and nonpolar ice caps, although covering shorter time-scales, can supplement the findings based on ice cores from the polar regions. In particular, alpine ice cores are expected to bridge the gaps in our understanding of the geographical distribution of past climatic and environmental conditions, including the impacts of human activities on the local surroundings (Thompson and others, 1988).

However, in contrast to polar ice masses, alpine glaciers are susceptible to an overall net loss of surface snow by wind erosion because of their relatively small scale (Wagenbach, 1989; Schöner and others, 2002). In addition, alpine glaciers often receive negligible precipitation in one or more seasons (e.g. Rikha Samba glacier, Nepal Himalaya (Fujita and others, 2001); Lugge, Lugge II and Thorthormi glaciers, Bhutan Himalaya (Suzuki, 2004); and July 1st glacier, Qilian Shan, west China (unpublished data from A. Sakai, 2004). This means that the common dating method involving annual-layer counting of seasonal variations in chemical concentrations and oxygen isotope ratios $\left(\delta^{18} \mathrm{O}\right)$, which requires a regular distribution of precipitation through the years (Eichler and others, 2000), often cannot be applied to alpine glaciers (e.g. Schwikowski and others, 1999; Olivier and others, 2003). Therefore, to obtain annual information

*Present address: Department of Environmental Sciences, Faculty of Science, Shinsu University, Asahi 3-2-1, Matsumoto 390-8621, Japan. about past climate and past environmental conditions in an alpine region, another dating method is required.

To solve this dating problem, we need other markers that represent specific seasons, yet can independently deposit in layers without snow. With such markers, one can divide a year's deposition into seasonal layers even if some seasonal layers are missing. Moreover, a method that can identify seasonal layers itself may enable high-resolution analysis in ice-core studies. Detailed observations of snow stratigraphy and density have been used on arctic ice caps to identify the four seasonal layers in each year (Bourgeois, 1990, 2000). This has been done by analyzing the snow types and density to find the ice layers and other seasonal layers and thus determining the summer melt surface. However, the method is limited to firn and is more difficult to use on alpine glaciers because surface melting occurs not only in summer but also in spring and autumn. Also, the meltwater percolates and refreezes lower down to form ice layers and thus alters the density throughout a snowpack. Hence, other methods are needed.

To develop a dating method that is applicable to ice cores from alpine glaciers, we turned our attention to the seasonality of pollen preserved in glacier bodies. Pollen grains are scattered in different seasons, depending on the taxa. Moreover, ice cores from alpine glaciers typically contain more than 1000 grains $\mathrm{L}^{-1}$ of pollen because they are usually within a few tens of kilometers of pollen sources (Godwin, 1949; Heusser, 1954; Ambach and others, 1966; Haeberli and others, 1983; Liu and others, 1998; Reese and Liu, 2002, 2005; Reese and others, 2003; Nakazawa and others, 2004). This is in contrast to polar ice sheets where the pollen mostly originates from sources hundreds to thousands of kilometers away, where the ice typically contains only $10-100$ grains $\mathrm{L}^{-1}$ (Fredskild and 

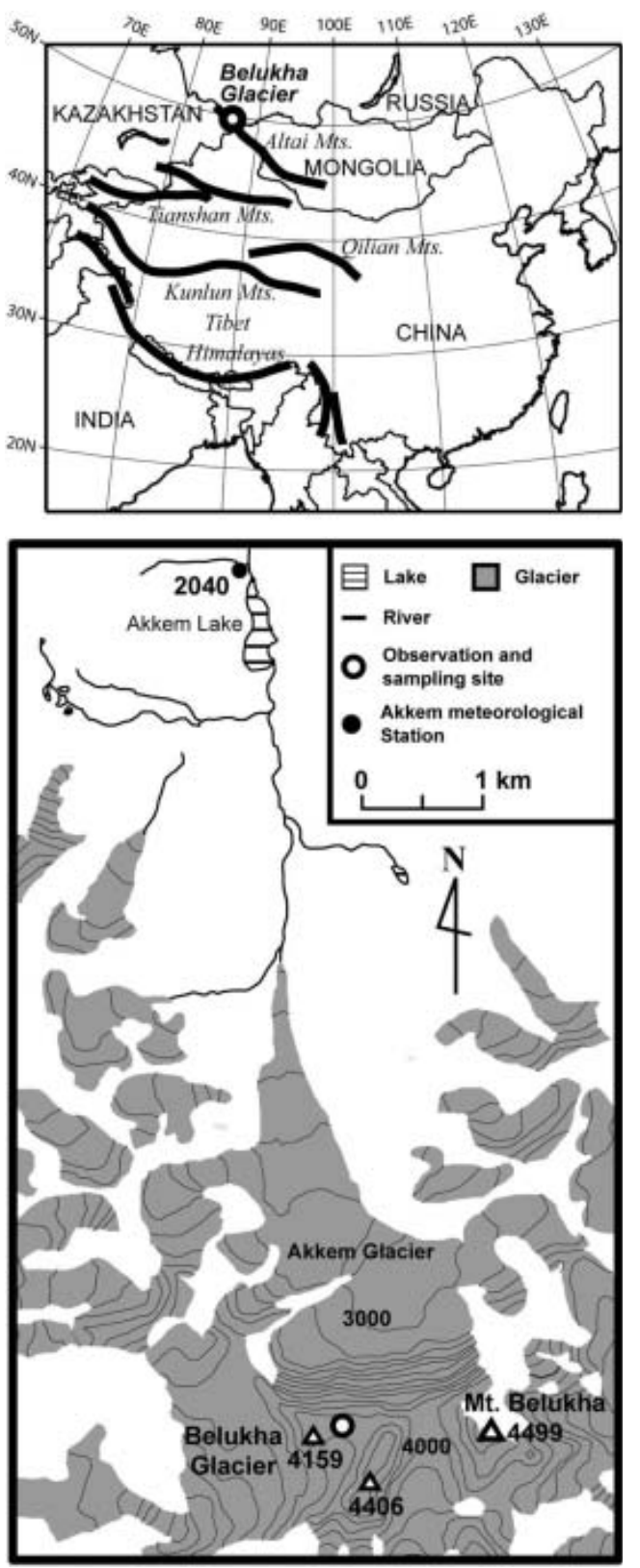

Fig. 1. Location of Belukha glacier in the Altai Republic, Russian Federation.

Wagner, 1974; Lichti-Federovich, 1975; McAndrews, 1984; Bourgeois and others, 1985; Short and Holdsworth, 1985; Koerner and others, 1988; Bourgeois, 1990, 2000). The high pollen count led Nakazawa and others (2004) to analyze an ice core from Altai glacier, Russia for pollen dating using samples of only $10 \mathrm{~mL}$ of melted water. They found that pollen grains could be good markers of summer layers as well as annual layers if Pinaceae and Artemisia pollen were used. Ice cores from alpine glaciers typically contain various pollen taxa. Thus, by including additional pollen taxa, it should be possible to extend the method developed by Nakazawa and others (2004) to allow the separation of several seasonal layers. Moreover, this extended model may allow dating of ice cores with missing layers, provided there is a net annual deposition.

However, Reese and Liu (2002) and Reese and others (2003) found significant spatial variations in pollen concentrations in surficial snow samples (the top $5 \mathrm{~cm}$ ) on tropical ice caps in the Andean Altiplano. Later, they studied the surface snow samples on Quelccaya ice cap in the Peruvian Altiplano and found that the pollen deposition (percentages and concentrations) in August 2000 differed significantly from the same measurements in June 2001 (Reese and Liu, 2005). If different pollen species have different spatial variations, or if some regions have an insufficient pollen concentration in some years, the pollen-dating method may be unreliable. In the case of the Andean Altiplano study, they did not examine the vertical variations of pollen concentrations, and therefore it is not clear whether the spatial and interannual variations are a problem for the present method.

The purpose of the present study is to test the method of Nakazawa and others (2004) and extend their method to the separation of seasonal layers. The glacier in our study is Belukha glacier in Russia's Altai mountains (Fig. 1), which is about 80 km west of Nakazawa and others' (2004) study site.

So far, ice cores of lengths 140 and $171 \mathrm{~m}$ have been obtained from the glacier by Olivier and others (2003) and Takeuchi and others (2004). Long-term meteorological records dating from the 1950s are available at the Akkem meteorological station (2040 m a.s.I.), which is $7 \mathrm{~km}$ north of the glacier and within the same basin (Fig. 1). Akkem receives $55 \%$ of its annual precipitation $(534 \mathrm{~mm}$ on average) during summer (June-August) and only 5\% through winter precipitation (December-February). Olivier and others (2003) reported that, presumably due to wind erosion and a lack of consistent winter precipitation, the use of $\delta^{18} \mathrm{O}$ to identify annual layers in the $140 \mathrm{~m}$ ice core was ambiguous. They also found, without providing a reason, that ice lenses were not useful for identifying annual layers. Instead therefore, they dated the core using tritium and ${ }^{210} \mathrm{~Pb}$ activity records. However, activity records do not provide sufficient resolution for analyses of annual and seasonal changes. The $171 \mathrm{~m}$ core has not been dated.

\section{STUDY AREA AND METHODS}

The daily depositions and annual deposition between July 2001 and July 2002 were measured using an automatic snowgauge and five stakes on the accumulation area of the west plateau of Belukha glacier $\left(49^{\circ} 49^{\prime} \mathrm{N}, 86^{\circ} 34^{\prime} \mathrm{E}\right.$; 4110 ma.s.l.). The plateau is at such a high elevation that any disturbance of the climate signal from meltwater in snow should be small. Avalanches have not been reported in the region. The locations of the stakes (ST) and snow pit (P) are shown in Figure 2. An automatic snowgauge was set at stake 2 (ST2 in Fig. 2). However, due to battery trouble on the data logger, the daily deposition data were obtained only until 27 October 2001. In July 2002, data from four stakes were recovered. Stake 1 was lost. On 13 July 2002, snow was taken from a $2.42 \mathrm{~m}$ pit for pollen and chemical analysis. The samples were taken consecutively at intervals ranging from 0.02 to $0.16 \mathrm{~m}$, with short intervals near the surface and in ice layers in order to study chemical alternation in the pit.

The reconstruction of paleovegetation and paleoclimate from ice, lacustrine and marine cores through pollen analysis is typically based on individual pollen percentages. They are calculated on the basis of the pollen sum. In that method, the sum of total identifiable pollen in a sample must exceed a few hundred grains to be statistically significant. However, our method is focused on the seasonality of 
pollen. Therefore, the classification and counting were done only for the major pollen types. Moreover, the pollen types of plants that have the same flowering season were regarded as one group. This helped to both shorten the analysis time per sample and reduce the sample volume required.

For the pollen analysis, samples of $10 \mathrm{~mL}$ were deemed necessary to provide sufficient water for analysis, even for ice-core samples of small volume. Each sample was filtered through a hydrophilic PTFE membrane filter with pore size $0.2 \mu \mathrm{m}$. The pollen grains on the filters were then counted by viewing them through a microscope. To keep the process simple and to prevent any pollen loss, we used no chemical treatment and no centrifuge operation on the samples. Because we did not remove the inner parts of the pollen grain chemically, Betulaceae could be identified only at the family level and we could not distinguish between Abies and Picea. Hence, we classified the pollen into the following four groups: Betulaceae, Abies + Picea, Pinus and Artemisia. In our samples, the total pollen count ranged from 0 to 522 (mean \pm SD: $47 \pm 95$; median: 17 ) grains, and the uncounted grains were fewer than the counted grains.

\section{RESULTS AND DISCUSSION}

\subsection{Results of pollen analysis}

Pollen analysis of the pit samples showed that the most abundant pollen types were Betulaceae, Pinaceae (Abies, Picea and Pinus) and Artemisia. The plants that produce these pollen are common within a few tens of kilometers of the glacier. According to a study on plants in Russia's Altai region (Luchik, 1970), the flowering season of Betulaceae, Abies and Picea is in late spring, mainly May, whereas that for Pinus is 1-2 months later, mainly in June. Unfortunately, Luchik did not report the flowering season of Artemisia. However, Artemisia typically flowers in early autumn. Thus, we assumed that the Artemisia flowering season near the glacier is in late August and September. The pollen-dispersal season for a given species coincides with its flowering season, which depends on the locality including the altitude, with some variation in dates of pollen dispersal depending on the individual plant. Therefore, we have assumed the pollen season for a given species in the region of the glacier lasts a few months, with each pollen type having the peak month stated above.

Each vertical pollen profile in the pit has two pollen-rich regions in Figure 3. The Betulaceae-rich and Abies + Picearich layers occur at $0.68-1.37 \mathrm{~m}$ and from $2.22 \mathrm{~m}$ to the bottom at $2.42 \mathrm{~m}$; the Pinus-rich layers occur at 0.00 (surface) to $1.05 \mathrm{~m}$ and $1.78-2.42 \mathrm{~m}$ depths; and the Artemisia-rich layers appear from the surface to $0.04 \mathrm{~m}$ and $1.37-1.84 \mathrm{~m}$ depths. Moreover, the pollen-depth distributions are consistent with the pollen seasons. Specifically, the Pinus-rich layers are above the Betulaceae-rich and Abies + Picea-rich layers, the Artemisia-rich layers are above the Pinus-rich layers, and the Betulaceae-rich and Abies + Picea-rich layers are above the Artemisia-rich layer. Because two high values of each pollen concentration occur at different depths, it is clear that the $2.42 \mathrm{~m}$ deep pit includes a whole year's deposition. Also, the regular pollen distribution supports our assumption that significant secondary pollen depositions by wind storms are unlikely.

We assume the peak positions identify the high seasons of pollen dispersal. Hence, from Figure 3, the Betulaceae and

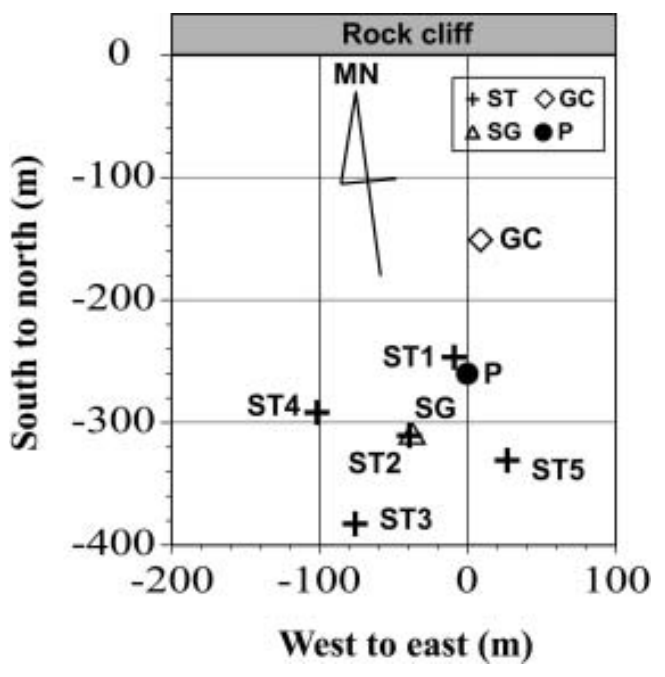

Fig. 2. Location of stakes (ST), glacier camp (GC), automatic snowgauge (SG) and pit (P) on the plateau of Belukha glacier. $\mathrm{MN}$ denotes the direction of magnetic north.

Abies + Picea peaks at 2.32-2.42 m and 0.99-1.05 m depths roughly correspond to May in 2001 and 2002, and the Pinus peaks at $2.02-2.12 \mathrm{~m}$ and surface to $0.04 \mathrm{~m}$ depths can be regarded as about June in 2001 and 2002, respectively. There is support for the 2002 Pinus peak marking June as this pollen was also measured in the surface sample of 13 July 2002. The Pinus pollen grains that form the peak were probably deposited later than the date of the peak, i.e. nearer 13 July, because the summer period in this region has frequent summer precipitations that would wash the grains into the snowpack. Accordingly, the date of the 2002 Pinus peak slightly differs from that in the study of Luchik (1970), with the difference being only about 10 days later than June. Hence, it seems reasonable here to assume that the Pinus peaks can mark June. In general, the peak dispersal season of a given pollen species in a region is almost the same every year. Thus, it is reasonable to assume that the Betulaceae and Abies + Picea peaks can be used to identify May in view of the study of Luchik (1970). However, the true 2001 peak of Betulaceae and Abies + Picea may be below $2.42 \mathrm{~m}$. Also, the true 2002 peak of Pinus could be after 13 July 2002. The Artemisia peak in 2001 is spread out, showing a rich layer without a clear maximum.

Seasonal layers are determined from these peaks as follows. The increment from 1.81 to $2.42 \mathrm{~m}$ is regarded as the summer of 2001, being between the pollen peaks that mark May (Betulaceae and Abies + Picea) and the summerautumn boundary (the boundary between Pinus-rich and Artemisa-rich layers). The summer increment should strictly be regarded as snowfall between late-spring and earlyautumn pollen peaks, according to the argument in Nakazawa and others (2004). However, the depth of $1.81 \mathrm{~m}$, where the Pinus pollen concentration decreases to about 0.0 grains $\mathrm{mL}^{-1}$ and the Artemisia pollen concentration starts to increase, is defined here as the boundary of summer and autumn because the region of high Artemisia values in 2001 has no distinct and prominent peak.

The depth of $1.37 \mathrm{~m}$ should be close to the boundary between autumn and spring. The dispersal of airborne pollen grains is typically a minimum in winter because no plants flower in winter. Accordingly, the concentration of pollen in 


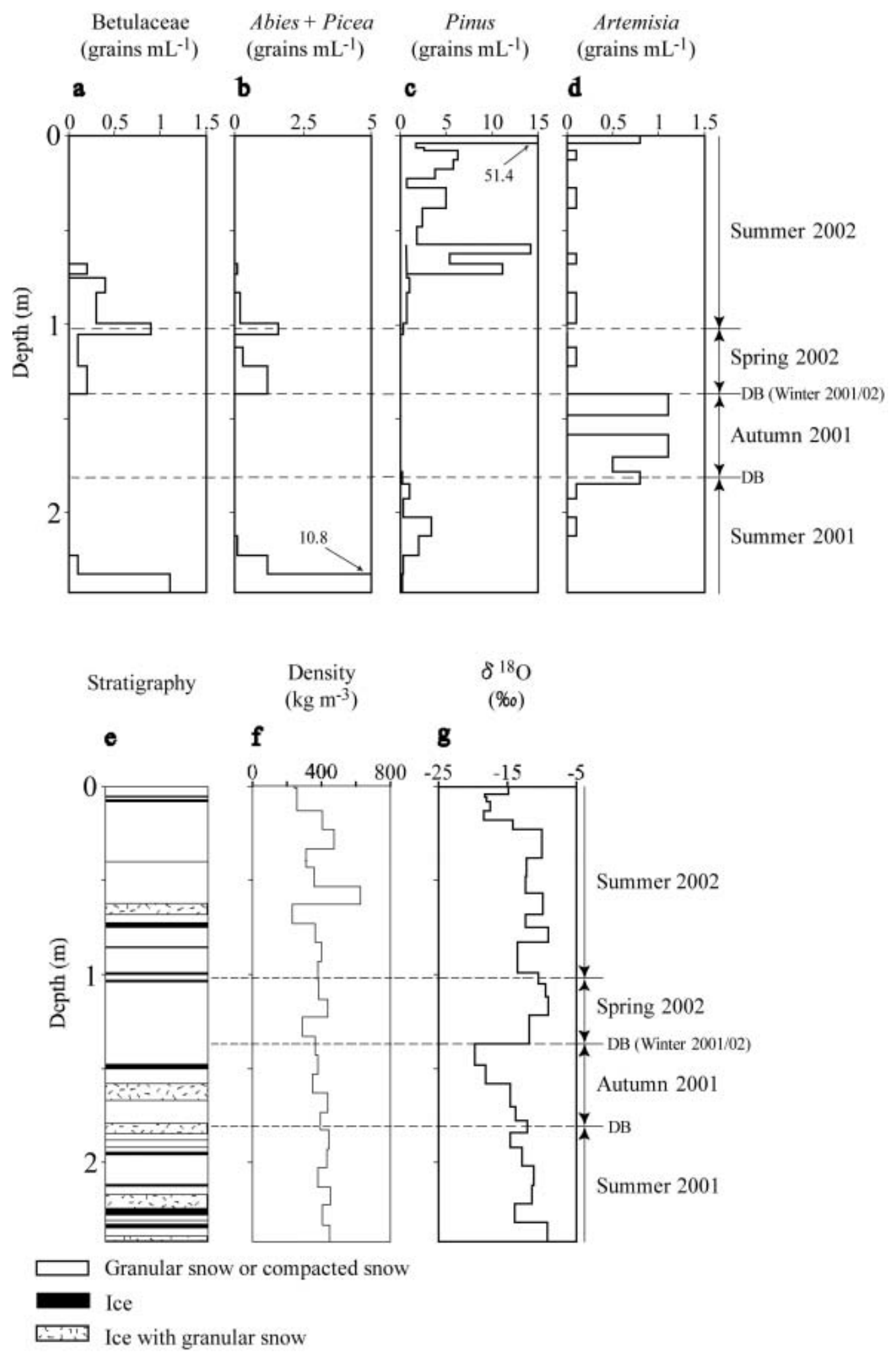

Fig. 3. Vertical profiles from the pit samples on Belukha glacier. Pollen concentrations of (a) Betulaceae, (b) Abies + Picea, (c) Pinus and (d) Artemisia measured in July 2002. (e) Physical stratigraphy measured in July 2002. (f) Density profiles measured in July 2002. (g) Oxygen isotope ratios $\left(\delta^{18} \mathrm{O}\right)$ measured in July 2002. DB marks the discontinuous boundary due to wind erosion. The broken lines indicate seasonal boundaries estimated from the pollen profiles.

the winter layer is typically $<0.5$ grains $\mathrm{mL}^{-1}$ (Haeberli and others, 1983). However, the 2001 autumn layer derived from the Artemisia-rich layers directly contacts the 2002 spring layer derived from the Betulaceae- and Picea + Abiesrich layers without any intervening pollen-poor layers. This indicates that the snow deposition during the winter of 2001/ 02 was either negligible or mostly eroded by wind.

The increment at $1.02-1.37 \mathrm{~m}$ depth is likely to be the spring increment of 2002 up until the pollen peaks in May appear. With these layer assignments, the layer 
Table 1. Observed and reconstructed snow thickness for 1 year's accumulation in 2001/02 and for snow deposition after a wind erosion event in autumn 2001. Errors are calculated from the ranges of snow sampling

\begin{tabular}{lll}
\hline $\begin{array}{l}\text { Annual snow deposition, } \\
\text { 2001/02 }\end{array}$ & $2.26 \pm 0.14$ & $2.05 \pm 0.07$ \\
$\begin{array}{l}\text { Snow deposition after a wind } \\
\text { erosion event, autumn } 2001\end{array}$ & $1.91 \pm 0.14$ & $1.81 \pm 0.03$ \\
\hline
\end{tabular}

between $1.02 \mathrm{~m}$ and the surface must be the 2002 summer layer, representing the accumulation during the period about May-July. An alternative scheme using the first abrupt increase in Pinus pollen concentration at $0.7 \mathrm{~m}$ depth may be useful for defining the spring-summer boundary. However, instead we decided to use the peaks as a marker so that we could determine the specific months.

To summarize the main points made in this subsection: The $2.42 \mathrm{~m}$ deep pit includes a whole year's deposition between summer 2001 and summer 2002. If one assumes the depth of $2.42 \mathrm{~m}$ is the 2001 Betulaceae and Abies + Picea peak, the annual deposition between May 2001 and May 2002 is $1.35 \mathrm{~m}$. Similarly, if one assumes the surface is the 2002 Pinus peak, the annual deposition between July 2001 and July 2002 is $2.05 \mathrm{~m}$. However, the true 2001 peak of Betulaceae and Abies + Picea is likely to be below $2.42 \mathrm{~m}$; also, the true 2002 peak of Pinus is likely to be after 13 July 2002. Thus, the annual deposition is probably larger than $2.05 \mathrm{~m}$. In addition, the seasonal deposition pattern shows that snow deposition increases during summer and decreases during winter; indeed, there appears to be negligible net winter deposition during 2001/02.

\subsection{Comparison with meteorological and in situ measurements}

Here we show that the seasonal and annual layers determined from pollen analysis are consistent with the meteorological data and in situ measurements of surface level.

The annual deposition between 18 July 2001 and 13 July 2002 was $2.26 \pm 0.14 \mathrm{~m}$ in snow $(0.87 \pm 0.06 \mathrm{~m}$ w.e. $)$ from the four stake measurements (Fujita and others, 2004). This is consistent with the $2.05 \pm 0.07 \mathrm{~m}(0.79 \pm 0.02 \mathrm{~m}$ w.e. $)$ difference observed between the 2001 and 2002 Pinus peaks (Table 1). Pinus peaks were chosen for comparison because they are contemporaneous with the stake observations. The error in the pollen-derived value was calculated from the range of thicknesses of the samples that included pollen peaks, namely the thickness of $0.10 \mathrm{~m}$ from the $2.02-2.12 \mathrm{~m}$ sample and $0.04 \mathrm{~m}$ from the 0.00 $0.04 \mathrm{~m}$ sample. Moreover, the good agreement supports the finding that the 2001 Pinus peak appeared in about May on the glacier, as well as the 2002 Pinus peak, and thus the high season of other pollen types also seems to be consistent with the flowering seasons determined by Luchik (1970). As the Pinaceae and Artemisia pollen from $10 \mathrm{~mL}$ samples of Sofiyskiy glacier in Russia's Altai

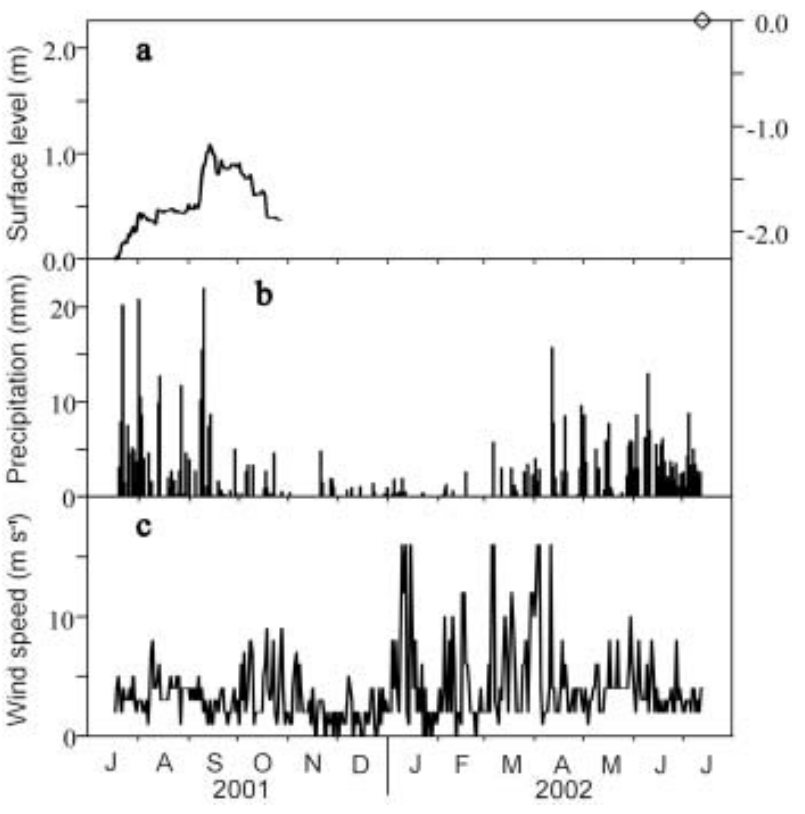

Fig. 4. Snow level on Belukha glacier and meteorological conditions. (a) Daily changes in relative surface levels on the plateau of Belukha glacier. The ordinate on the lefthand side has an origin at the surface level of 18 July 2001 . The ordinate on the righthand side has an origin at the surface level of 13 July 2002. The curve covers 18 July-27 October 2001, as measured with an automatic snowgauge. The diamond shows the surface level of 27 October 2002, as measured with stakes. (b) Daily maximum wind speed at the Akkem meteorological station between 18 July 2001 and 13 July 2002. (c) Daily precipitation at the Akkem meteorological station between 18 July 2001 and 13 July 2002 .

Mountains was also shown to be reliable for annual-layer counting (Nakazawa and others, 2004), the method of using only $10 \mathrm{~mL}$ meltwater samples may be useful for many alpine glaciers.

The meteorological data and snowgauge records indicated a significant influence of wind erosion on the surface level. Figure $4 \mathrm{a}$ shows the daily changes in relative surface level between 18 July and 27 October 2001. The surface level increased more than $1 \mathrm{~m}$ from July to September 2001, at roughly the same time the Akkem meteorological station recorded high values of precipitation (Fig. 4b). Then, in October, the surface level decreased rapidly to $0.35 \mathrm{~m}$, a level that corresponds to the surface level of the first half of August. At the same time, the daily maximum wind speed increased at the Akkem meteorological station (Fig. 4c). Such a rapid decrease in snow depth cannot be explained by snow compaction. Also, the loss by sublimation should be negligible due to the relatively high latitude and consequently the low amount of radiationinduced sublimation. In addition, the snow-pit observation of 2002 showed no indication of heavy melting (Fig. 3e). Thus, the prominent lowering of the surface level is likely to be due to wind erosion. This means that the late-autumn layer did not accumulate on the early-autumn surface, but instead accumulated on the surface deposited in August. After 27 October, the observation site received more new snow and, according to the stake measurements and the automatic snowgauge, the snow level reached a thickness of $1.91 \pm 0.14 \mathrm{~m}$ in July 2002 (the diamond mark in Fig. 4a). 
Table 2. Precipitation at Akkem meteorological station during each period, and percentage of the total precipitation from 27 October 272001 to 13 July 2002 that fell in each period

\begin{tabular}{lcc}
\hline & Precipitation & $\begin{array}{c}\% \text { of the total precipitation } \\
(307 \mathrm{~mm}) \text { from 27 October } \\
2001 \text { to 13 July } 2002\end{array}$ \\
& $\mathrm{~mm}$ & 63 \\
1 May-13 July 2002 & 192 & 44 \\
\hline 1 May-13 July 2002 & 135 & \\
\hline
\end{tabular}

The snow-stake and snowgauge data support the 2001 summer-autumn boundary at $1.81 \mathrm{~m}$ depth that was estimated using pollen analysis. The Pinus pollen season in 2001 apparently ended on 27 October, after which snow deposition resumed, whereas it would have been accumulating on the glacier surface even in the first half of August. Thus, the $1.81 \pm 0.03 \mathrm{~m}$ depth is estimated to have been deposited in the first half of August since this depth is the top layer at which Pinus pollen was detected in the 2001 layer. Specifically, the ice above this depth probably accumulated after 27 October, whereas the ice below it probably accumulated in the first half of August. In addition, this value is close to the $1.91 \pm 0.14 \mathrm{~m}$ depth from the stake measurements and the automatic snowgauge (Table 1). Thus, we conclude that the meteorological data support our pollen analysis of the snow pit. Further support comes from the stratigraphy and Artemisia pollen profile. The snow type at $1.81 \mathrm{~m}$ depth was ice with granular snow. The bond between partly metamorphosed snow grains is stronger than that between fresh snow grains, so further wind erosion may have been prevented for the ice at $1.81 \mathrm{~m}$ depth. In addition, the absence of an early-autumn layer in 2001 would explain why the region of high Artemisia values in 2001 has no distinct and prominent peak.

Our pollen analysis shows that the winter layer of 2001/ 02 is missing or negligible. At the Akkem meteorological station, the daily maximum wind speeds during the winter are much higher than those during September and October when the wind erosion event occurred on the glacier. In general, surface melting on the glacier, which consolidates the dry snow, tending to prevent it from blowing away, does not occur in the winter. Furthermore, there may have been little or no snow deposition on the glacier during winter 2001/02 since the total precipitation from December to February at the Akkem meteorological station was only $17 \mathrm{~mm}$. Accordingly, we interpret the negligible or nonexistent winter layer as due to a combination of negligible snowfall and wind erosion. Wind erosion also may have eroded some of the autumn layer in 2001. Therefore, our analysis of the pollen and meteorological data supports hj>the prediction of Olivier and others (2003) that winter layers were largely missing from the Belukha glacier ice core.

The layer between $1.02 \mathrm{~m}$ and the surface, in other words between the Betulaceae and Abies + Picea peaks and the Pinus peak, is probably the deposition between May and 13 July 2002. The thickness is calculated as $383 \mathrm{~mm}$ w.e. from the density profile in Figure $3 \mathrm{f}$, which corresponds to $56.0 \%$ of the total deposition of $684 \mathrm{~mm}$ w.e. $(1.81 \mathrm{~m}$ in snow) after the wind erosion event in autumn 2001. In contrast, the total precipitation at the Akkem meteorological station from 27 October 2001 through 13 July 2002, which corresponds to the precipitation after the wind erosion event, was $307 \mathrm{~mm}$ (Table 2). In addition, the precipitation between 1 May and 13 July was $192 \mathrm{~mm}$, whereas that between 31 May and 13 July was $135 \mathrm{~mm}$ (Table 2). The 2001 high-pollen season of Betulaceae, Abies and Picea on the glacier is expected to have been mainly in May, whereas the 2002 peak of Pinus was detected at the 13 July surface of the glacier. Thus, the $192-135 \mathrm{~mm}$ of precipitation recorded at the Akkem meteorological station seems to be synchronized with the $1.02 \mathrm{~m}$ thickness of snow deposited on the glacier between May and 13 July 2002. Furthermore, the ratio of the precipitation for 1 May-13 July to the precipitation for 27 October-13 July is $63 \%$, whereas that for 31 May-13 July to 27 October-13 July is $44 \%$ (Table 2 ). These values are close to the estimated ratio of $56 \%$, which is the ratio of the deposition between May and 13 July to the total deposition after the wind erosion event. We cannot exclude the possibility that wind erosion of the winter layer of 2001/02 and of the autumn layer of 2001 occurred, and thus the ratio of $56 \%$ may be an overestimate. However, any overestimation due to erosion is probably small since there was little snow deposition on the glacier during that season, as indicated by the low precipitation at the Akkem meteorological stations (Fig. 4b). Therefore, the good agreement supports our argument that the near-surface snow deposition of $1 \mathrm{~m}$ occurred in May-July, corresponding to the period between the pollen high seasons. In particular, it is clear that most of the annual deposition occurred during the summer.

Comparisons between the pollen data and the observed data in this subsection have shown that pollen data can be used to identify the annual boundaries precisely. Moreover, the pollen data were used to detect the summer layers in 2001 and 2002, and the winter layer in 2001/02. Therefore, the 2001 autumn layer between summer 2001 and winter 2001/02, and the 2002 spring layer between winter 2001/02 and summer 2002, can be regarded as accurate identifications of the seasonal layers. However, the conclusions are based on 1 year of data on one glacier and therefore we need to test the method by using many more years of data not only on this glacier but also on other glaciers.

\subsection{Oxygen isotopic composition and stratigraphy}

Dating methods for ice cores based on $\delta^{18} \mathrm{O}$ or chemical concentrations are difficult to apply to the alpine glacier ice cores with seasonal missing layers (e.g. Schwikowski and others, 1999; Olivier and others, 2003). Consequently, the interpretation of ice cores in alpine glaciers such as Belukha glacier, where wind erosion and/or little seasonal precipitation occurs, has proved difficult. This is consistent with our findings. The $\delta^{18} \mathrm{O}$, density and stratigraphy through the depth of the snow pit show ambiguous seasonal variation (Fig. 3e-g). Ice layers, which mark the summer melt surface on arctic glaciers (Bourgeois, 1990, 2000), appear throughout the stratigraphy. Densities in the snow pit vary from 233 to $623 \mathrm{~kg} \mathrm{~m}^{-3}$. However, almost every layer has roughly the same average density of about $400 \mathrm{~kg} \mathrm{~m}^{-3}$, and the profile shows no seasonality. In addition, the $\delta^{18} \mathrm{O}$ profile shows two minima within 1 year of deposition: one from 0.04 to $0.18 \mathrm{~m}$, and the other from 1.37 to $1.48 \mathrm{~m}$. These minima occur within the 2002 summer layer and at the boundary between autumn 2001 and spring 2002, respectively. As 
there are two $\delta^{18} \mathrm{O}$ minima and several ice layers within a year, neither of these identifiers is useful for dating cores or pit walls of this glacier. This agrees with the findings of Olivier and others (2003).

\section{CONCLUSIONS}

We have shown that pollen analysis can be used to determine seasonal layers in an alpine glacier (including alpine ice caps), and consequently that it can be used to determine the annual deposition, even for sites affected by wind erosion. Samples as small as $10 \mathrm{~mL}$ can serve for pollen analysis. Thus pollen analysis with small samples can be used to date ice cores from alpine glaciers such as Belukha glacier. In addition, it should complement other high-resolution chemical, biological and physical analyses and thus improve the resolution of annual and seasonal layers in ice cores from alpine glaciers. Pollen dating is presently the only useful method for dating ice cores from alpine glaciers where other conventional methods of dating are unreliable due to wind erosion and low seasonal precipitation. The present study was based on 1 year of data on a single glacier. With additional research over longer time periods and for glaciers in several regions, this method may provide a greater understanding of past climates and environments in non-polar regions.

\section{ACKNOWLEDGEMENTS}

We thank G.I. Nenasheva and O.V. Ostain of Altai State University for useful advice and materials on plant life in Russia's Altai region. We thank two reviewers for valuable comments and criticisms. This research was supported by the 21st Century COE Program (No. G-4, Nagoya University) from the Ministry of Education, Culture, Sports, Science and Technology of Japan; the US Department of Energy (DEA107) research project; 'Aeolian Dust Experiment on Climate Impact (ADEC)' and 'Ice core analysis with cryomicrobes on glaciers in Chinese arid region' funded by Special Coordination Funds for Promoting Science and Technology; the Center Research Project of Hydrospheric Atmospheric Research Center, Nagoya University; and the Oasis Project (Historical evolution of adaptability in an oasis region to water resource changes), promoted by the Research Institute for Humanity and Nature, Kyoto, Japan.

\section{REFERENCES}

Ambach, W., S. Bortenschlager and H. Eisner. 1966. Pollen-analysis investigation of a $20 \mathrm{~m}$ firn pit on the Kesselwandferner (Ötztal Alps). J. Glaciol., 6(44), 233-236.

Bourgeois, J.C. 1990. Seasonal and annual variation of pollen content in the snow of a Canadian High Arctic ice cap. Boreas, 19(4), 313-322.

Bourgeois, J.C. 2000. Seasonal and interannual pollen variability in snow layers of arctic ice caps. Review of Palaeobotany and Palynology, 108, 17-36.

Bourgeois, J.C., R.M. Koerner and B.T. Alt. 1985. Airborne pollen: a unique mass tracer, its influx to the Canadian High Arctic. Ann. Glaciol., 7, 109-116.

Eichler, A. and 7 others. 2000. Glaciochemical dating of an ice core from upper Grenzgletscher (4200 m a.s.I.). J. Glaciol., 46(154), 507-515.
Fredskild, B. and P. Wagner. 1974. Pollen and fragments of plant tissue in core samples from the Greenland ice cap. Boreas, 3(3), 105-108.

Fujita, K., F. Nakazawa and B. Rana. 2001. Glaciological observations on Rikha Samba Glacier in Hidden Valley, Nepal Himalayas, 1998 and 1999. Bulletin of Glaciological Research, Data Center for Glacier Research, 18, $31-35$.

Fujita, K., N. Takeuchi, V. Aizen and S. Nikitin. 2004. Glaciological observations on the plateau of Belukha Glacier in the Altai Mountains, Russia from 2001 to 2003. Bulletin of Glaciological Research, 21, 57-64.

Godwin, H. 1949. Pollen analysis of glaciers in special relation to the formation of various types of glacier bands. J. Glaciol., 1(6), 325-333.

Grootes, P.M., M. Stuiver, J.W.C. White, S. Johnsen and J. Jouzel. 1993. Comparison of oxygen isotope records from the GISP2 and GRIP Greenland ice cores. Nature, 366(6455), 552-554.

Haeberli, W., U. Schotterer, D. Wagenbach, H.H. Schwitter and S. Bortenschlager. 1983. Accumulation characteristics on a cold, high-Alpine firn saddle from a snow-pit study on Colle Gnifetti, Monte Rosa, Swiss Alps. J. Glaciol., 29(102), 260-271.

Heusser, C.J. 1954. Palynology of the Taku Glacier snow cover, Alaska and its significance in the determination of glacier regimen. Am. J. Sci., 252(5), 291-308.

Jouzel, J. and 16 others. 1993. Extending the Vostok ice-core record of palaeoclimate to the penultimate glacial period. Nature, 364(6436), 407-412.

Koerner, R.M., J.C. Bourgeois and D.A. Fisher. 1988. Pollen analysis and discussion of time-scales in Canadian ice cores. Ann. Glaciol., 10, 85-91.

Lichti-Federovich, S. 1975. Pollen analysis of ice core samples from the Devon Island Ice Cap. Geological Survey of Canada Paper 75-1A, 441-444.

Liu, K.B., Z. Yao and L.G. Thompson. 1998. A pollen record of Holocene climatic changes from the Dunde ice cap, QinghaiTibetan Plateau. Geology (Boulder), 26(2), 135-138.

Lorius, C., J. Jouzel, D. Raynaud, J. Hansen and H.L. Treut. 1990. The ice-core record: climate sensitivity and future greenhouse warming. Nature, 347(6289), 139-145.

Luchik, Z.I. 1970. Introduction of trees and bushes in Altai territory. Moscow, Kolos.

McAndrews, J.H. 1984. Pollen analysis of the 1973 ice core from Devon Island glacier, Canada. Quat. Res., 22(1), 68-76.

McManus, J.F., G.C. Bond, W.S. Broecker, S. Johnsen, L. Labeyrie and S. Higgins. 1994. High-resolution climate records from the North Atlantic during the last interglacial. Nature, 371(6495), 326-329.

Nakazawa, F. and 8 others. 2004. Application of pollen analysis to dating of ice cores from lower-latitude glaciers. J. Geophys. Res., 109(F4), 4001. (10.1029/2004JF000125.)

Olivier, S. and 10 others. 2003. Glaciochemical investigation of an ice core from Belukha Glacier, Siberian Altai. Geophys. Res. Lett., 30(19), 2019. (10.1029/2003GL018290.)

Reese, C.A. and K.B. Liu. 2002. Pollen dispersal and deposition on the Quelccaya Ice Cap, Peru. Phys. Geogr., 23, 44-58.

Reese, C.A. and K.B. Liu. 2005. Inter-annual variability in pollen dispersal and deposition on the tropical Quelccaya Ice Cap. Professional Geographer, 57(2), 185-197.

Reese, C.A., K.B. Liu and K.R. Mountain. 2003. Pollen dispersal and deposition on the ice cap of Mt. Parinacota, southwestern Bolivia. Arct. Antarct. Alp. Res., 35(4), 469-474.

Schöner, W., I. Auer, R. Böhm, L. Keck and D. Wagenbach. 2002. Spatial representativity of air-temperature information from instrumental and ice-core-based isotope records in the European Alps. Ann. Glaciol., 35, 157-161.

Schwikowski, M., A. Döscher, H. Gäggeler and U. Schotterer. 1999. Anthropogenic versus natural sources of atmospheric sulphate from an Alpine ice core. Tellus, 51B(5), 938-951. 
Short, S.K. and G. Holdsworth. 1985. Pollen, oxygen isotope content and seasonality in an ice core from the Penny Ice Cap, Baffin Island. Arctic, 38(3), 214-218.

Suzuki, R. 2004. Estimation on glacier melting in Lunana region, Bhutan. (M.S. thesis, Nagoya University.)

Takeuchi, N. and 7 others. 2004. A report on ice core drilling on the western plateau of Mt. Belukha in the Altai Mountain Range in 2003. Polar Meteorol. Glaciol., 18, 121-133.
Thompson, L.G., M.E. Davis, E. Mosley-Thompson and K. Liu. 1988. Pre-Incan agricultural activity recorded in dust layers in two tropical ice cores. Nature, 336(6201), 763-765.

Wagenbach, D. 1989. Environmental records in alpine glaciers. In Oeschger, H. and C.C. Langway, Jr, eds. The environmental record in glaciers and ice sheets. Chichester, etc., John Wiley and Sons, 69-83.

MS received 25 October 2004 and accepted in revised form 14 July 2005 